Clinical Rehabilitation

\title{
Improvement in Over Active Bladder Symptoms in Patients Using Functional Electrical Stimulation of the Common Peroneal Nerve for Walking.
}

\begin{tabular}{|c|c|}
\hline Journal: & Clinical Rehabilitation \\
\hline Manuscript ID & CRE-2018-7061.R2 \\
\hline Manuscript Type: & Original Article \\
\hline Date Submitted by the Author: & 11-May-2018 \\
\hline Complete List of Authors: & $\begin{array}{l}\text { Hare, Nicola; University College London Hospitals NHS Foundation Trust } \\
\text { National Hospital for Neurology and Neurosurgery, Therapies and } \\
\text { Rehabilitation } \\
\text { Georgopoulos, Petros; University College London Hospitals NHS Foundation } \\
\text { Trust National Hospital for Neurology and Neurosurgery, Uroneurology } \\
\text { Philips, Kate; University College London Hospitals NHS Foundation Trust } \\
\text { National Hospital for Neurology and Neurosurgery, Therapies and } \\
\text { Rehabilitation } \\
\text { Johnson, Joanne; University College London Hospitals NHS Foundation } \\
\text { Trust National Hospital for Neurology and Neurosurgery, Therapies and } \\
\text { Rehabilitation } \\
\text { Seary, Coralie; University College London Hospitals NHS Foundation Trust } \\
\text { National Hospital for Neurology and Neurosurgery, Therapies and } \\
\text { Rehabilitation } \\
\text { Panicker, Jalesh ; University College London Hospitals NHS Foundation } \\
\text { Trust National Hospital for Neurology and Neurosurgery, Uroneurology; } \\
\text { University College London, Institute of Neurology } \\
\text { Stevenson, Valerie; University College London Hospitals NHS Foundation } \\
\text { Trust National Hospital for Neurology and Neurosurgery, Therapies and } \\
\text { Rehabilitation; University College London, Institute of Neurology }\end{array}$ \\
\hline Keywords: & $\begin{array}{l}\text { Functional Electrical Stimulation, Overactive bladder, Multiple Sclerosis, } \\
\text { Percutaneous tibial nerve stimulation }\end{array}$ \\
\hline
\end{tabular}

\section{SCHOLARONE}

Manuscripts 


\begin{abstract}
Objective: Functional Electrical Stimulation is used to improve walking speed and reduce falls in people with upper motor neurone foot drop. Following anecdotal observations of changes in bladder symptoms, an observational study was performed to explore this association further.
\end{abstract}

Design: 47 consecutive patients attending for set up with Functional Electrical Stimulation during a six month period were asked to complete a questionnaire assessing bladder symptoms (ICIQ-OAB) at baseline and 3 months during routine appointments.

Subjects: $35(75 \%)$ had multiple sclerosis, the other 12 subjects had a total of 9 diagnoses including 3 with stroke. Other conditions included cerebral palsy, motor neurone disease, hereditary spastic paraparesis, meningioma and spinocerebellar ataxias.

Results: Improvement in over active bladder symptoms was not significant in the whole cohort however was in patients with multiple sclerosis $(n=35$; mean change in ICIQ-OAB score 1.0, $p=0.043)$. Specifically, significant improvements were seen in urgency and urge incontinence in multiple sclerosis patients. There was a significant negative correlation of moderate strength within the multiple sclerosis cohort between baseline walking speed and subsequent change in ICIQ-OAB score (correlation coefficient of $r=-0.40, p=0.046)$. Thus greater changes in bladder symptoms were seen with lower baseline walking speeds.

Conclusion: The results of this exploratory study suggest that Functional Electrical Stimulation use does improve over active bladder symptoms in people with multiple 
sclerosis. Further exploration is needed to study this association and explore whether the mechanism is similar to that of Percutaneous Tibial Nerve Stimulation, a recognised treatment for the over active bladder. 


\section{Introduction}

Functional Electrical Stimulation is a recognised management strategy for people with foot drop secondary to an upper motor neurone disorder, approved as effective by the UK National Institute for Health and Clinical Excellence (NICE). ${ }^{1}$ Surface skin electrodes are placed over the Common Peroneal Nerve and/or the tibialis anterior muscle activating the dorsiflexors and evertors, thus improving the ability to clear the foot during swing phase of gait; improving stability and reducing falls. ${ }^{2}$

Percutaneous Tibial Nerve Stimulation has been shown to be a safe, clinically and cost-effective treatment (also NICE approved) for the management of drug refractory overactive bladder symptoms in people with neurological disorders. ${ }^{3-6}$ It involves inserting a stimulating needle 3 fingerbreadths above the medial malleolus close to the Tibial Nerve and placing a surface electrode on the same leg near the arch of the foot. Most treatment schedules consist of 12 outpatient sessions lasting 30 minutes each (adjustable pulse intensity 0-10mA, fixed pulse width of 200 microseconds, frequency $20 \mathrm{~Hz})^{3,4}$ The mechanism by which Percutaneous Tibial Nerve Stimulation works to improve bladder dysfunction remains uncertain. It is likely that stimulation of a somatic peripheral nerve results in alteration of signaling centrally in the spinal cord interneurons and peripherally at sympathetic and parasympathetic postganglionic nerve terminals and synapses involved in the voiding reflex, thereby resulting in an alteration of bladder functions. ${ }^{7,8}$

In our experience some patients report improvement in lower urinary tract symptoms after the commencement of Functional Electrical Stimulation to aid walking. The Tibial and Common Peroneal nerves are the terminal branches of the sciatic nerve, both are derived from L4-S3 sharing a common innervation, we therefore 
hypothesise that Functional Electrical Stimulation may have effects on lower urinary tract functions similar to Percutaneous Tibial Nerve Stimulation treatment. We therefore studied our clinic population for any possible relationship between the use of Functional Electrical Stimulation and changes in bladder symptoms, to inform the design of a future study.

\section{Methods}

Consecutive patients attending for set up with Functional Electrical Stimulation using the Odstock Dropped Foot Stimulator (ODFS®) Pace device (single channelled, foot switch triggered: maximum amplitude $100 \mathrm{~mA}, 350 \mu$ s pulse, $40 \mathrm{~Hz}$ ) during a six month period were asked to complete a questionnaire on their urinary functions at baseline and 3 months during their routine physiotherapy appointments. The ICIQ-OAB questionnaire provides a brief and robust measure to assess the impact of overactive bladder symptoms. It is scored from 0-16 with greater values indicating increased symptom severity of urinary frequency, urgency, nocturia and urinary incontinence. .,10 $^{9}$

No further details were collected regarding bladder management and this continued as normal practice. The service evaluation was reviewed and registered with the Clinical Governance Department.

\section{Statistical Analysis}

Data was analysed using SPSS; the Wilcoxon Signed-Rank Test was used to compare ICIQ-OAB scores at baseline and 3 months and Spearman's Rank 
Correlation Coefficient to assess the relationship between baseline walking speed and ICIQ-OAB scores with change in ICIQ-OAB scores.

\section{Results}

Of the 47 subjects proceeding to Functional Electrical Stimulation set up within the 6 month period $35(75 \%)$ had a diagnosis of multiple sclerosis, the other 12 subjects had a total of 9 diagnoses including 3 with stroke. Other conditions included cerebral palsy, motor neurone disease, hereditary spastic paraparesis, meningioma and spinocerebellar ataxias.

There was a significant improvement of the ICIQ-OAB score (a reduction in score indicates an improvement in bladder symptoms) in the multiple sclerosis population over the 3 month period $(p=0.043)$. When urinary symptoms were separately analysed, significant improvements were seen in urgency and urge incontinence (Table 1).

There was a significant negative correlation of moderate strength in multiple sclerosis patients between baseline walking speed and the subsequent change in ICIQ-OAB score (correlation coefficient of $r=-0.40, p=0.046)$. Thus greater improvements in bladder symptoms were seen with lower baseline walking speeds (Figure 1).

With respect to bladder impairment, a significant negative correlation of moderate strength was shown between baseline ICIQ-OAB score and change in score; thus patients with worse bladder symptoms at baseline had smaller improvement in ICIQ- 
OAB scores (Whole group $r=-0.466, p=0.001$, multiple sclerosis group $r=-0.442$, $p=0.008)$ (Figure 2).

\section{Discussion}

The results of this study demonstrate a statistically significant improvement in overactive bladder symptoms after 3 months of functional electrical stimulation use to improve walking in multiple sclerosis patients. The one unit reduction (17\%) observed reflects a recognised clinically important difference. ${ }^{11}$

When individual symptoms of bladder dysfunction were considered, the main areas demonstrating improvement were urinary urgency and urge incontinence. The impact of bladder dysfunction may of course be influenced by improvements in mobility and speed of accessing toileting facilities particularly with regard to incontinence. However it is unlikely that participants would report changes in urgency simply as a result of an orthotic effect on their walking. It would however be invaluable to correlate these findings with objective evidence of improvements in urinary dysfunction through urodynamic studies.

Despite significant changes in the sub-scores of the ICIQ-OAB assessing urinary urgency and urge incontinence, the change in overall score was not significant when all patients were considered together. We postulate that this may reflect the differences in the neurological insult; multiple sclerosis has a heavy burden of spinal cord pathology whereas the other group was predominantly comprised of cerebral origin disorders. This association is perhaps borne out further by the significant correlation within the multiple sclerosis cohort between baseline walking speed and 
the subsequent change in ICIQ-OAB score, demonstrating that perhaps those patients with a higher spinal cord disease burden (slower walking speeds) had greater improvement in overactive bladder symptoms. Studies of Percutaneous Tibial Nerve Stimulation have also demonstrated particular efficacy in patients with multiple sclerosis and for all aspects of their urinary symptoms, ${ }^{12,13}$

Analysis revealed a significant negative moderate correlation between baseline $I C I Q-O A B$ score and change in score, demonstrating that people with less severe bladder symptoms at baseline were more likely to show improvements following Functional Electrical Stimulation use. This warrants further investigation with urodynamic studies but is an interesting observation as it suggests individuals with mild urinary symptoms may be able to avoid drug treatments and be managed solely through neuromodulation.

The mode of delivery of Percutaneous Tibial Nerve Stimulation and Functional Electrical Stimulation clearly differ. Percutaneous Tibial Nerve Stimulation is usually delivered as a course of weekly 30 minute treatment sessions over 12 weeks giving a total dosage of 6 hours in 3 months, whereas Functional Electrical Stimulation may deliver this much in a single day albeit of a reduced intensity. This study did not collect information on dosage (step count) or intensity (amplitude), two important aspects to consider in future study designs.

This is an observational study and has limitations, a further study designed to specifically evaluate efficacy with pathophysiological correlates including urodynamics is warranted. We do not propose that Functional Electrical Stimulation be used to treat urinary symptoms but it does however for the first time indicate that its use may improve bladder dysfunction and could have implications for 
commencing or continuing bladder treatments in users of Functional Electrical Stimulation.

\section{Clinical Message}

- Functional Electrical Stimulation to aid walking may improve neurogenic bladder symptoms particularly in patients with multiple sclerosis

\section{Acknowledgements}

The work was undertaken at UCLH/UCL Institute of Neurology and JNP is supported in part by funding from the United Kingdom's Department of Health NIHR Biomedical Research Centres funding scheme.

\section{References}

1) National Institute for health and Clinical Excellence (NICE). Functional electrical stimulation for drop foot of central neurological origin. NICE interventional procedure guidance (IPG 278). 2009. Available from: https://www.nice.org.uk/Guidance/IPG278

2) Street T, Taylor P, Swain I. Effectiveness of functional electrical stimulation on walking speed, functional walking category, and clinically meaningful changes 
for people with multiple sclerosis. Archives of Physical Medicine and Rehabilitation 2015;96(4): 667-672.

3) Govier FE, Litwiller S, Nitti V, Kreder KJ Jr, Rosenblatt P. Percutaneous afferent neuromodulation for the refractory overactive bladder: results of a multicenter study. J Urol. 2001;165(4):1193-1198.

4) Peters KM, Carrico DJ, Perez-Marrero RA, et al. Randomized trial of percutaneous tibial nerve stimulation versus Sham efficacy in the treatment of overactive bladder syndrome: results from the SUmiT trial. J Urol. 2010;183(4):1438-1443.

5) Finazzi-Agro E, Petta F, Sciobica F, Pasqualetti $P$, Musco S, Bove P. Percutaneous tibial nerve stimulation effects on detrusor overactivity incontinence are not due to a placebo effect: a randomized, double-blind, placebo controlled trial. J Urol. 2010;184(5):2001-2006.

6) National Institute for health and Clinical Excellence (NICE). Percutaneous posterior tibial nerve stimulation for overactive bladder syndrome. NICE interventional procedure guidance (IPG362). 2010. Available from: https://www.nice.org.uk/Guidance/IPG362

7) Moossdorff-Steinhauser $\mathrm{H}$, Berghmans $B$. Effects of percutaneous tibial nerve stimulation on adult patients with overactive bladder syndrome: A systematic review. Neurourology and Urodynamics 2013;32(3):206-214. 
8) De Groat WC, Griffiths D, Yoshimura N. Neural control of the lower urinary tract. Compr Physiol. 2015;5(1):327-396.

9) Jackson S, Donovan J, Brookes S, Eckford S, Swithinbank L, Abrams P. The Bristol Female Lower Urinary Tract Symptoms questionnaire: development and psychometric testing. Br J Urol. 1996 Jun;77(6):805-12.

10) Iciq.net. (2017). ICIQ I OAB Module. [online] Available at: http://www.iciq.net/ICIQ.OABmodule.html [Accessed 10 March. 2018]

11)Verghese T S, Tryposkiadis K, Arifeen K, Middleton L, Latthe P M. Minimal clinically important difference (MCID) for the international Consultation on Incontinence Questionnaire- Overactive Bladder (ICIQ- OAB). Abstract 638, ICS Florence 2017 https://www.ics.org/Abstracts/Publish/349/000638.pdf

12) Kabay S, Kabay SC, Yucel M, et al. The clinical and urodynamic results of a 3-month percutaneous posterior tibial nerve stimulation treatment in patients with multiple sclerosis-related neurogenic bladder dysfunction. Neurourol Urodyn 2009;28(8):964-968.

13)Canbaz Kabay S, Kabay S, Mestan E, Cetiner M, Ayas S, Sevim M, Ozden H, Karaman HO. Long term sustained therapeutic effects of percutaneous posterior tibial nerve stimulation treatment of neurogenic overactive bladder in multiple sclerosis patients: 12-months results. Neurourol Urodyn. 2017 Jan;36(1):104-110. 
Table 1

Subject demographic and ICIQ-OAB Scores

\begin{tabular}{|c|c|c|c|c|c|c|}
\hline \multirow{3}{*}{$\begin{array}{l}\text { Age (years); } \\
\text { mean (range) }\end{array}$} & \multicolumn{2}{|l|}{$\begin{array}{l}\text { All } \\
n=47\end{array}$} & \multicolumn{2}{|c|}{$\begin{array}{l}\text { Multiple Sclerosis } \\
n=35\end{array}$} & \multicolumn{2}{|c|}{$\begin{array}{l}\text { Other } \\
n=12\end{array}$} \\
\hline & \multicolumn{2}{|c|}{$51(32-70)$} & \multicolumn{2}{|c|}{$52(37-70)$} & \multicolumn{2}{|c|}{$49(32-66)$} \\
\hline & Baseline & $\begin{array}{l}3 \\
\text { months }\end{array}$ & Baseline & $\begin{array}{l}3 \\
\text { months }\end{array}$ & Baseline & $\begin{array}{l}3 \\
\text { months }\end{array}$ \\
\hline $\begin{array}{l}\text { ICIQ-OAB } \\
\text { Mean (SD) }\end{array}$ & $\begin{array}{l}6.00 \\
(3.28)\end{array}$ & $\begin{array}{l}5.60 \\
(2.92)\end{array}$ & $\begin{array}{l}6.00 \\
(5.00)\end{array}$ & $\begin{array}{l}5.00 \\
(5.00)^{*}\end{array}$ & $\begin{array}{l}3.42 \\
(1.73)\end{array}$ & $\begin{array}{l}4.08 \\
(2.39)\end{array}$ \\
\hline $\begin{array}{l}\text { Question3 } \\
\text { Frequency } \\
\text { Median (IQR) }\end{array}$ & $1(2)$ & $1(2)$ & $1(2)$ & $1(2)$ & $0(0)$ & $0(1.75)$ \\
\hline $\begin{array}{l}\text { Question } 4 \\
\text { Nocturia } \\
\text { Median (IQR) }\end{array}$ & $1(1)$ & $1(1)$ & $2(1)$ & $1(1)$ & $1(0)$ & $1(1)$ \\
\hline $\begin{array}{l}\text { Question } 5 \\
\text { Urgency } \\
\text { Median (IQR) }\end{array}$ & $2(2)$ & $2(2)^{*}$ & $2(1)$ & $2(2)^{*}$ & $1(1)$ & $1(1)$ \\
\hline $\begin{array}{l}\text { Question } 6 \\
\text { Urge Urinary } \\
\text { Incontinence } \\
\text { Median (IQR) }\end{array}$ & $1(1)$ & $1(1)^{*}$ & $2(2)$ & $1(1)$ & $1(1.75)$ & $1(1)$ \\
\hline
\end{tabular}

*Significant change $p<0.05$

MS multiple sclerosis; SD standard deviation; IQR= Interquartile range; 
Legends:

Figure 1. Scatterplot of baseline walking speed and change in ICIQ-OAB score in multiple sclerosis subjects

Figure 2. Scatterplot of baseline ICIQ-OAB score and change in ICIQ-OAB score in all subjects 
Figure 1

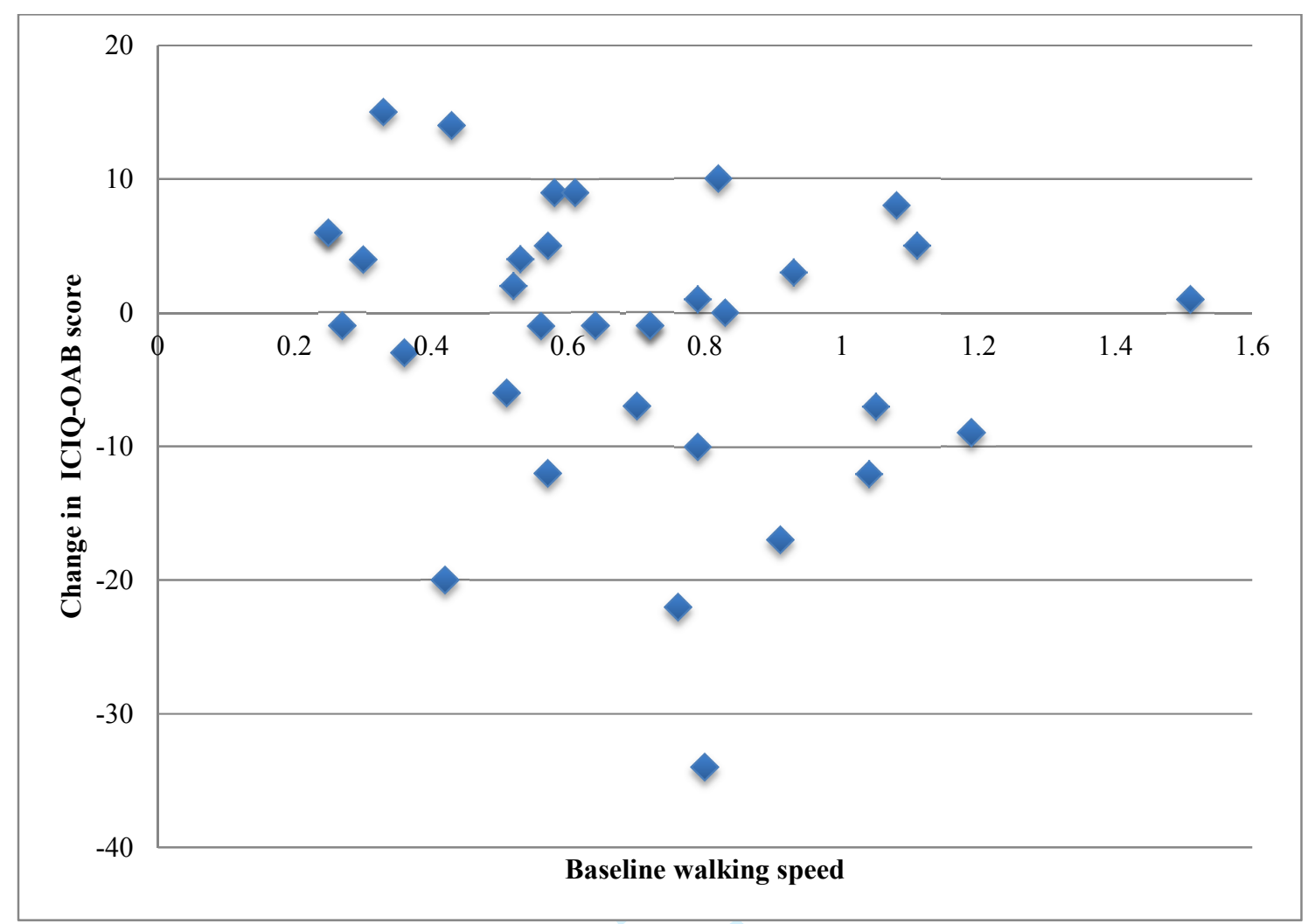

http://mc.manuscriptcentral.com/clinrehab 
Figure 2

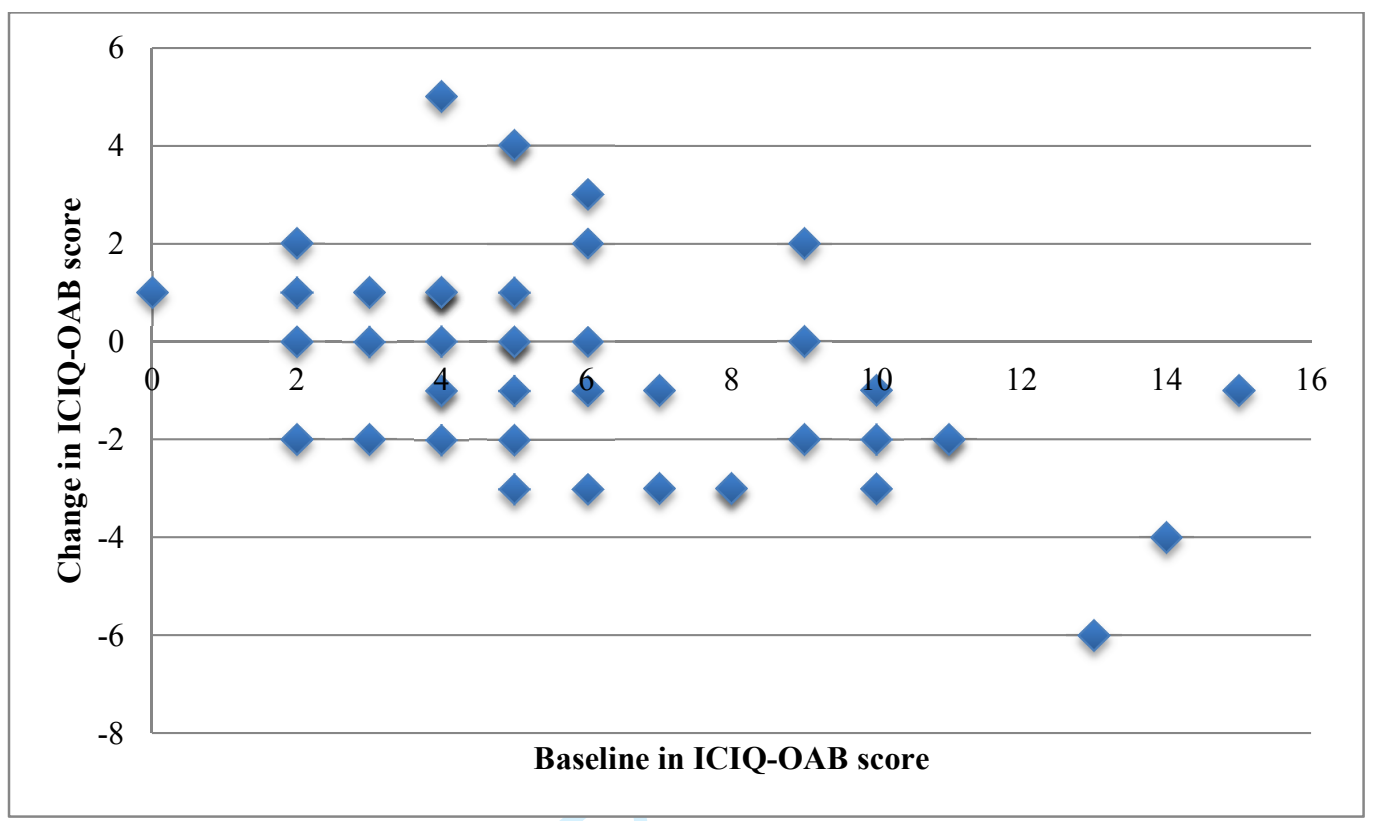

